\title{
Biomarkers of Cellular Apoptosis and Necrosis in Donor Myocardium Are Not Predictive of Primary Graft Dysfunction
}

\author{
O. SZARSZOI ${ }^{1}$, J. BESIK ${ }^{1}$, M. SMETANA ${ }^{1}$, J. MALY ${ }^{1}$, M. URBAN ${ }^{1}$, J. MALUSKOVA ${ }^{2}$, \\ A. LODEREROVA ${ }^{2}$, L. HOSKOVA ${ }^{3}$, Z. TUCANOVA ${ }^{1}$, J. PIRK $^{1}$, I. NETUKA $^{1}$
}

${ }^{1}$ Department of Cardiovascular Surgery, Institute for Clinical and Experimental Medicine, Prague, Czech Republic, ${ }^{2}$ Department of Pathology, Institute for Clinical and Experimental Medicine, Prague, Czech Republic, ${ }^{3}$ Department of Cardiology, Institute for Clinical and Experimental Medicine, Prague, Czech Republic

Received June 16, 2015

Accepted June 22, 2015

On-line October 8, 2015

\section{Summary}

Primary graft dysfunction (PGD) is a life-threatening complication among heart transplant recipients and a major cause of early mortality. Although the pathogenesis of PGD is still unclear, ischemia/reperfusion injury has been identified as a predominant factor. Both necrosis and apoptosis contribute to the loss of cardiomyocytes during ischemia/reperfusion injury, and this loss of cells can ultimately lead to PGD. The aim of our prospective study was to find out whether cell death, necrosis and apoptosis markers present in the donor myocardium can predict PGD. The prospective study involved 64 consecutive patients who underwent orthotopic heart transplantation at our institute between September 2010 and January 2013. High-sensitive cardiac troponin $\mathrm{T}$ (hs-cTnT) as a marker of minor myocardial necrosis was detected from arterial blood samples before the donor's pericardium was opened. Apoptosis (caspase-3, active + pro-caspase-3, bcl-2, TUNEL) was assessed from bioptic samples taken from the right ventricle prior graft harvesting. In our study, $14 \%$ of transplant recipients developed PGD classified according to the standardized definition proposed by the ISHLT Working Group. We did not find differences between the groups in regard to hs-cTnT serum levels. The mean hs-cTnT value for the PGD group was $57.4 \pm 22.9 \mathrm{ng} / \mathrm{l}$, compared to $68.4 \pm 10.8 \mathrm{ng} / \mathrm{l}$ in the group without PGD. The presence and severity of apoptosis in grafted hearts did not differ between grafts without PGD and hearts that subsequently developed PGD. In conclusion, our findings did not demonstrate any association between measured myocardial cell death, necrosis or apoptosis markers in donor myocardium and PGD in allograft recipients. More detailed investigations of cell death signaling pathways in transplanted hearts are required.

\section{Key words}

Heart transplantation - Apoptosis • Necrosis - Primary graft dysfunction

\section{Corresponding author}

O. Szarszoi, Department of Cardiovascular Surgery, Institute for Clinical and Experimental Medicine, Vídeňská 1958/9, 14021 Prague 4, Czech Republic. Fax: +420 261081362.

E-mail: onsz@medicon.cz

\section{Introduction}

Primary graft dysfunction (PGD) is a lifethreatening complication among heart transplant recipients and a major cause of early mortality. PGD is currently defined as left ventricular, right ventricular or biventricular dysfunction that occurs within $24 \mathrm{~h}$ after surgery and is not associated with a discernible cause such as hyperacute rejection, pulmonary hypertension, or known surgical complications (Kobashigawa et al. 2014). Prior to the development of a standardized definition for PGD, the incidence of PGD in published studies varied between $2.3 \%$ and $28.2 \%$ (Russo et al. 2010, D'Alessandro et al. 2010, Lima et al. 2006, D'Ancona et al. 2010, Marasco et al. 2012, Oto et al. 2008, Segovia et al. 2011, Ibrahim et al. 2007).

Although the pathogenesis of PGD is still 
unclear, ischemia/reperfusion injury with myocardial stunning has been identified as a predominant factor (Iyer et al. 2011). Donor hearts are subjected to different types of insults during the transplant procedure, including brain death, hypothermic storage, warm ischemia and finally reperfusion, exacerbating post-transplant cardiac ischemia/reperfusion injury and decreasing allograft survival (Atkinson et al. 2013). There are two basic patterns of cell death: cell injury with swelling, known as oncosis; and cell injury with shrinkage, known as apoptosis. Oncosis leads to necrosis with karyolysis and stands in contrast to apoptosis, which leads to cell death with karyorhexis and cell shrinkage (Majno and Joris 1995). Both necrosis and apoptosis contribute to the loss of cardiomyocytes during ischemia/reperfusion injury, and this loss of myocytes can ultimately lead to PGD. Moreover, novel high-sensitive cardiac troponin T (hscTnT) assays have been developed and could be a useful marker of the minor myocardial necrosis associated with ischemia/reperfusion injury (Giannitsis and Katus 2009).

The aim of our prospective study thus was to determine whether selected markers of cell death, necrosis and apoptosis present in the donor myocardium can predict PGD.

\section{Patients and Methods}

\section{Patients}

The prospective study involved 64 consecutive patients who underwent orthotopic heart transplantation at our institute between September 2010 and January 2013. The study was approved by the human research ethics committee of our institute and written informed consent was obtained from all patients enrolled in the study. All patients were treated according to the current guidelines for the management of heart failure and transplantation. The standard criteria developed by our institute were used for donor selection. Myocardial protection was initiated with cardioplegic arrest, using St. Thomas crystalloid cardioplegic solution containing bicarbonate $\left(1500 \mathrm{ml}, \mathrm{pH} 7.4,4-10^{\circ} \mathrm{C}\right)$. Cardiac grafts were also stored in cold St. Thomas cardioplegic solution and transported on ice. Cold blood cardioplegia was administered at the beginning and subsequently at 20-min intervals during implantation.

\section{Troponin detection}

An arterial blood sample was taken before the donor's pericardium was opened. Each sample was centrifuged and the serum stored at $-70{ }^{\circ} \mathrm{C}$ until the study was completed. Hs-cTnT was detected using an electrochemiluminescent immunoassay ( $\mathrm{T}$ hs STAT, Cobas e411, Roche Diagnostics $\mathrm{GmbH}$, Mannheim, Germany) according to the manufacturer's recommendations. The parameters of the assay were as follows: lower limit of detection at $5 \mathrm{ng} / \mathrm{l}$, measuring range 3 to $10,000 \mathrm{ng} / \mathrm{l}, 10 \%$ intra-assay coefficient of variation at $13 \mathrm{ng} / \mathrm{l}$, intra-assay coefficient of variation $<3.2 \%$ and interassay coefficient of variation $<6.2 \%$ at a concentration of $12.6 \mathrm{ng} / \mathrm{l}$. The upper reference limit was set at $13.5 \mathrm{ng} / \mathrm{l}$.

\section{Histopathology}

Apoptosis was assessed from bioptic samples taken from the right ventricle prior to graft harvesting. The biopsy specimens were fixed in $10 \%$ formalin, embedded in paraffin, cut at $4 \mu \mathrm{m}$ and stained with hematoxylin-eosin (H\&E) and sirius red with elastica.

\section{Immunohistochemistry}

Immunohistochemical detection of caspase-3 (clone JHM 62, Novocastra, Leica Microsystems, UK) was performed on $4-\mu \mathrm{m}$ thick sections of paraffinembedded tissues using the Ventana BenchMark ULTRA system (Tucson, AZ, USA) and ultraView Universal DAB Detection Kit. Immunohistochemical detection of active + pro-caspase-3 (clone 31A1067, abcam, UK) and bcl-2 (clone 3.1, Novocastra, Leica Microsystems, UK) was performed on $4 \mu \mathrm{m}$-thick paraffin sections using a two-step indirect method. The slides were deparaffinized in xylene and rehydrated in graded ethanol. Antigen retrieval was performed using heatinduced epitope retrieval in a pH 8.0 EDTA buffer. Endogenous peroxidase was blocked with $0.3 \% \mathrm{H}_{2} \mathrm{O}_{2}$ in $70 \%$ methanol for $30 \mathrm{~min}$. The primary antibody was applied for $30 \mathrm{~min}$ at RT and detected using Histofine Simple Stain MAX PO (MULTI) Universal Immunoperoxidase Polymer, Anti-Mouse and Rabbit. Finally, the specimens were stained with Dako Liquid $\mathrm{DAB}+$ Substrate-Chromogen System (Dako, Glostrup, Denmark) for $5 \mathrm{~min}$ and counterstained with Harris's hematoxylin.

\section{TUNEL staining}

Apoptosis was assessed from bioptic samples taken from the right ventricle prior to graft harvesting. In situ detection of apoptosis by the TUNEL assay was performed on $4 \mu \mathrm{m}$-thick paraffin sections using 
a TUNEL peroxidase apoptosis detection kit (Roche Diagnostics GmbH, Germany) according to the manufacturer's instructions. Briefly, a $4 \mu \mathrm{m}$-thick deparaffinized sections were pretreated with proteinase $\mathrm{K}$ $(20 \mu \mathrm{g} / \mathrm{ml})$ for $10 \mathrm{~min}$ at $37^{\circ} \mathrm{C}$. After washing in PBS, the endogenous peroxidase was inactivated in $0.3 \% \mathrm{H}_{2} \mathrm{O}_{2}$ for $30 \mathrm{~min}$, followed by incubation with TUNEL Reaction Mixture (TdT enzyme and nucleotide mixture) at $37^{\circ} \mathrm{C}$ for one hour. After this incubation, sections were incubated with anti-fluorescein antibody conjugated with horseradish peroxidase at room temperature for $30 \mathrm{~min}$, followed by incubation with diaminobenzidine (DAB) solution. The slides were counterstained with hematoxylin and mounted. TUNEL-positive cells were examined under a light microscope. Apoptotic myocytes were identified by positive TUNEL staining.

In all immunohistochemical methods (caspase-3, active + pro-caspase- 3, bcl-2) and TUNEL, the slides were observed under an Olympus BX41 light microscope. The numbers of positive cells were counted in ten high-power fields (HPF), and then the average number of positive cells per HPF was used for statistical analysis.

\section{Statistical analysis}

Analysis was performed using Graph Pad Prism 5.0 software (GraphPad Prism version 5.00 for Windows, GraphPad Software, San Diego, CA, USA). Continuous data were reported as means $\pm \mathrm{SEM}$. Frequencies were calculated for qualitative data. Differences between the groups were compared using the Mann-Whitney U test. The Fischer exact test was used to test for group differences in qualitative data. Differences were assumed as statistically significant when $\mathrm{P}<0.05$.

\section{Results}

In our study, $14 \%$ of transplanted patients developed PGD classified according to the new standardized definition (Kobashigawa et al. 2014). There were no significant differences among the groups in regard to donor age $(40.4 \pm 1.8$ vs. $39.8 \pm 5.8)$ and gender (m/f $36 / 20$ vs. $3 / 5)$. The mean ischemic time was $141 \pm$ $7.3 \mathrm{~min}$ for the group without PGD and $157 \pm 16.7 \mathrm{~min}$ for the group with PGD. We did not observe differences among the groups in recipient age, gender, cause of heart failure, or use of mechanical circulatory support in allograft recipients. The data are shown in Table 1. Detailed data for patients with PGD are shown in Table 2.
Table 1. Demographic and baseline patient data.

\begin{tabular}{llll}
\hline & $\begin{array}{l}\text { nPGD } \\
(\mathbf{n = 5 6})\end{array}$ & $\begin{array}{l}\text { PGD } \\
(\mathbf{n = 8})\end{array}$ & \\
\hline $\begin{array}{l}\text { Donor age (years) } \\
\text { Recipient age } \\
\text { (years) }\end{array}$ & $40.4 \pm 1.8$ & $39.8 \pm 5.8$ & n.s. \\
$\begin{array}{l}\text { Donor gender } \\
\text { (male/female) }\end{array}$ & $52.2 \pm 1.8$ & $47.5 \pm 3.4$ & n.s. \\
$\begin{array}{l}\text { Recipient gender } \\
\text { (male/female) }\end{array}$ & $44 / 12$ & $3 / 5$ & n.s. \\
$\begin{array}{l}\text { Cause of heart } \\
\text { failure } \\
\text { (CAD/CMP/other) }\end{array}$ & $21 / 31 / 4$ & $1 / 5 / 2$ & n.s. \\
$\begin{array}{l}\text { Ischemic time } \\
\text { (min) }\end{array}$ & $141 \pm 7.3$ & $157 \pm 16.7$ & n.s. \\
$\begin{array}{l}\text { No. with pre- } \\
\text { transplant MCS }\end{array}$ & 15 & 4 & n.s. \\
\hline
\end{tabular}

nPGD - patients without primary graft dysfunction; PGD patients with primary graft dysfunction; $C A D$ - coronary artery disease; CMP - cardiomyopathy; MCS - mechanical circulatory support

Four patients were found to have moderate PGD-left ventricle and four patients PGD-right ventricle according to the new definition of PGD (Kobashigawa et al. 2014). Thirty-day survival in patients with PGD was $100 \%$.

We did not find differences among the groups in regard to hs-cTnT serum levels. The mean value of hscTnT for the group with PGD was 57.4 $\pm 22.9 \mathrm{ng} / \mathrm{l}$, compared to $68.4 \pm 10.8 \mathrm{ng} / 1$ in the group without PGD (Fig. 1).

The presence and severity of apoptosis in grafted hearts were detected by immunohistochemical staining for caspase-3, active + pro-caspase-3 and bcl-2. Moreover, apoptotic myocytes were identified by positive TUNEL staining. All measurements are shown in Figures 2 and 3. There were no significant differences between grafts without PGD and hearts that subsequently developed PGD.

\section{Discussion}

Our results show that in donor hearts that subsequently developed PGD, necrosis and apoptosis markers did not differ in comparison with hearts without PGD.

The role of biomarkers in PGD is still 
Table 2. Detailed data of patients with primary graft dysfunction.

\begin{tabular}{ccccccc}
\hline Patient & Donor gender & $\begin{array}{c}\text { Recipient } \\
\text { gender }\end{array}$ & $\begin{array}{c}\text { Ischemic time } \\
\text { (min) }\end{array}$ & PAR (Wu) & PGD-LV & PGD-RV \\
\hline 1 & M & M & 83 & 1.3 & yes (moderate) & yes \\
2 & M & M & 168 & 1.8 & no & yes \\
3 & M & M & 178 & 1.9 & no & yes \\
4 & F & F & 179 & 1.2 & no & yes \\
5 & F & F & 140 & 1.2 & no & yes \\
6 & F & M & 225 & 3.3 & yes (moderate) & yes \\
7 & F & M & 188 & 1.8 & yes (moderate) & no \\
8 & F & M & 100 & 2.9 & yes (moderate) & no \\
\hline
\end{tabular}

PAR - pulmonary arterial resistance; PGD-LV - left ventricle primary graft dysfunction; PGD-RV - right ventricle primary graft dysfunction; $\mathrm{M}$ - male; $\mathrm{F}$ - female

controversial. Several studies have been published on the role of biomarkers in the myocardium in an effort to determine whether they can predict PGD. Cardiac troponin is an established marker of cardiac necrosis with unchallenged myocardial tissue specificity and is routinely used for therapeutic decision-making in acute coronary syndromes (Giannitsis and Katus 2009). Some studies have correlated elevated troponins in potential donors with LV dysfunction, pulmonary edema, need for inotropic support, and worse outcomes in transplant recipients. Deibert et al. (2003) found that an elevated level of cardiac troponin I was a strong indicator of LV dysfunction in patients with non-traumatic subarachnoid hemorrhage. They concluded that this elevated level of cardiac troponin I was a good indicator of left ventricular dysfunction; however, cardiac dysfunction was reversible and should not necessarily preclude these patients from undergoing operative interventions or becoming heart donors. Boccheciampe et al. (2009) investigated the association between cardiac troponin I values and myocardial dysfunction in potential heart donors and the relationship between donors' cardiac troponin I values and recipients' early myocardial function, one-year survival and risk of rejection. They found that in potential donors, the level of cardiac troponin I was associated with myocardial dysfunction and could be helpful for organ selection. In contrast, cardiac troponin I values in heart donors were not associated with graft dysfunction or recipient survival after transplantation. Khush et al. (2007) performed a retrospective study to determine whether donor cardiac troponin I levels exceeding $1.0 \mu \mathrm{g} / 1$ are associated with adverse recipient outcomes. Although there was a non-significant trend towards longer post-transplant hospitalization in recipients of grafts from donor with higher cardiac troponin levels, modestly elevated cardiac troponin I in donors was not associated with a higher risk of recipient mortality or need for post-transplant mechanical circulatory support. This demonstrated that an elevated level of troponin alone should not be a contraindication for transplantation. On the other hand, Potapov et al. (2001) showed that an increased cardiac troponin value in donors (cardiac troponin I value $>1.6 \mathrm{mg} / \mathrm{l}$ and cardiac troponin $\mathrm{T}$ value $>0.1 \mathrm{mg} / \mathrm{l})$ was a predictor of early graft failure after heart transplantation and that the measurement of cardiac troponin levels in heart donors was useful for donor heart selection.

In summary, the question of whether troponin measured with conventional assays is predictive of PGD remains controversial, because literature demonstrates overall mixed results. A new hs-cTnT assay has recently been developed that decreases the diagnostic threshold to the 99th percentile value, i.e., troponin concentrations that are lower by a factor of 10 than those detectable with conventional assays can be measured (Giannitsis and Katus 2009). There are only limited studies investigating the use of hs-cTnT assay during heart transplant procedures. Erbel et al. (2012) tested the predictive power of hs-cTnT blood levels soon after heart transplantation in 141 allograft recipients. They demonstrate that patients who died within the first year after transplantation had significantly higher median hscTnT serum levels six weeks after transplantation. In multivariate analysis, hs-cTnT serum levels six weeks after transplantation emerged as an independent predictor for first-year mortality. Determining hs-cTnT may also be 


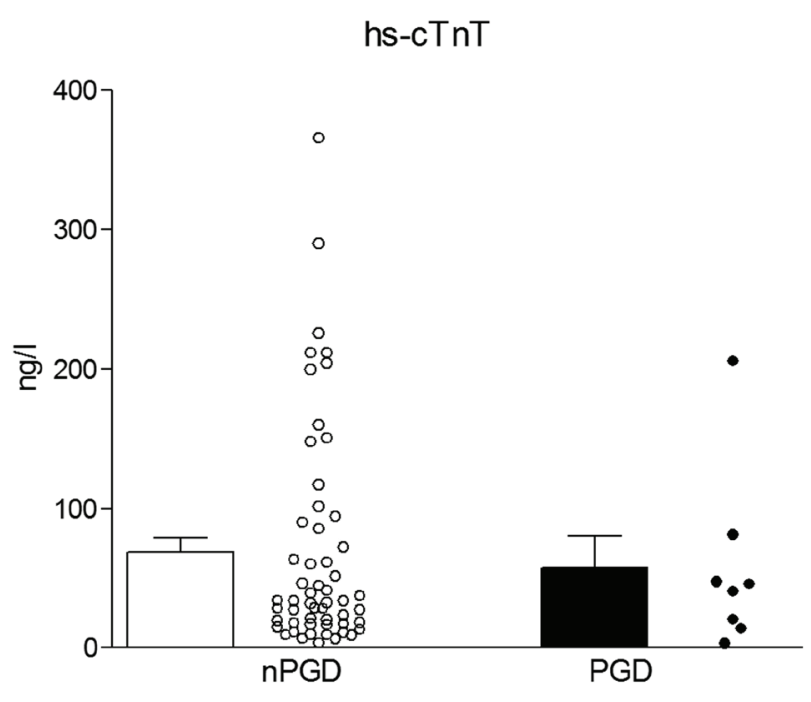

Fig. 1. High-sensitive cardiac troponin $T$ (hs-cTnT) serum level in patients without primary graft dysfunction (nPGD) and with primary graft dysfunction (PGD).
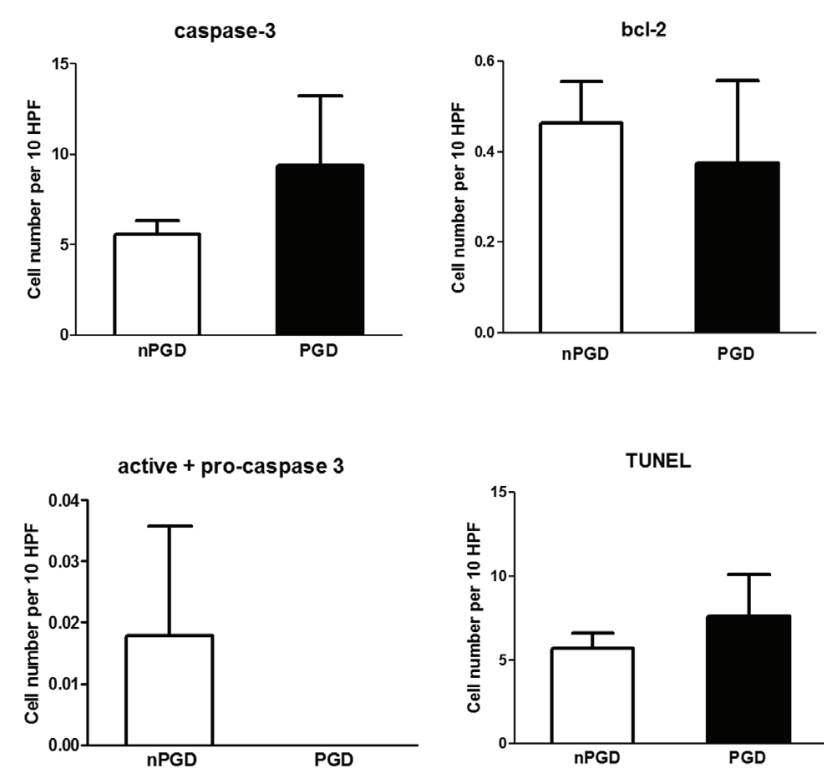

Fig. 2. Detection of caspase-3, active + pro-caspase-3, bcl-2 and TUNEL staining per ten high-power fields (HPF) in hearts without primary graft dysfunction (nPGD) and with primary graft dysfunction (PGD).

useful for excluding acute rejection after transplantation (Méndez et al. 2014). However, the relationship between hs-cTnT and PGD has not been assessed and more investigations are required.

Programmed cell death initiated prior to reperfusion may be a major mediator of post-operative PGD after donor heart transplantation. Molecular evidence for apoptosis has been previously investigated in transplanted hearts and in hearts not accepted for

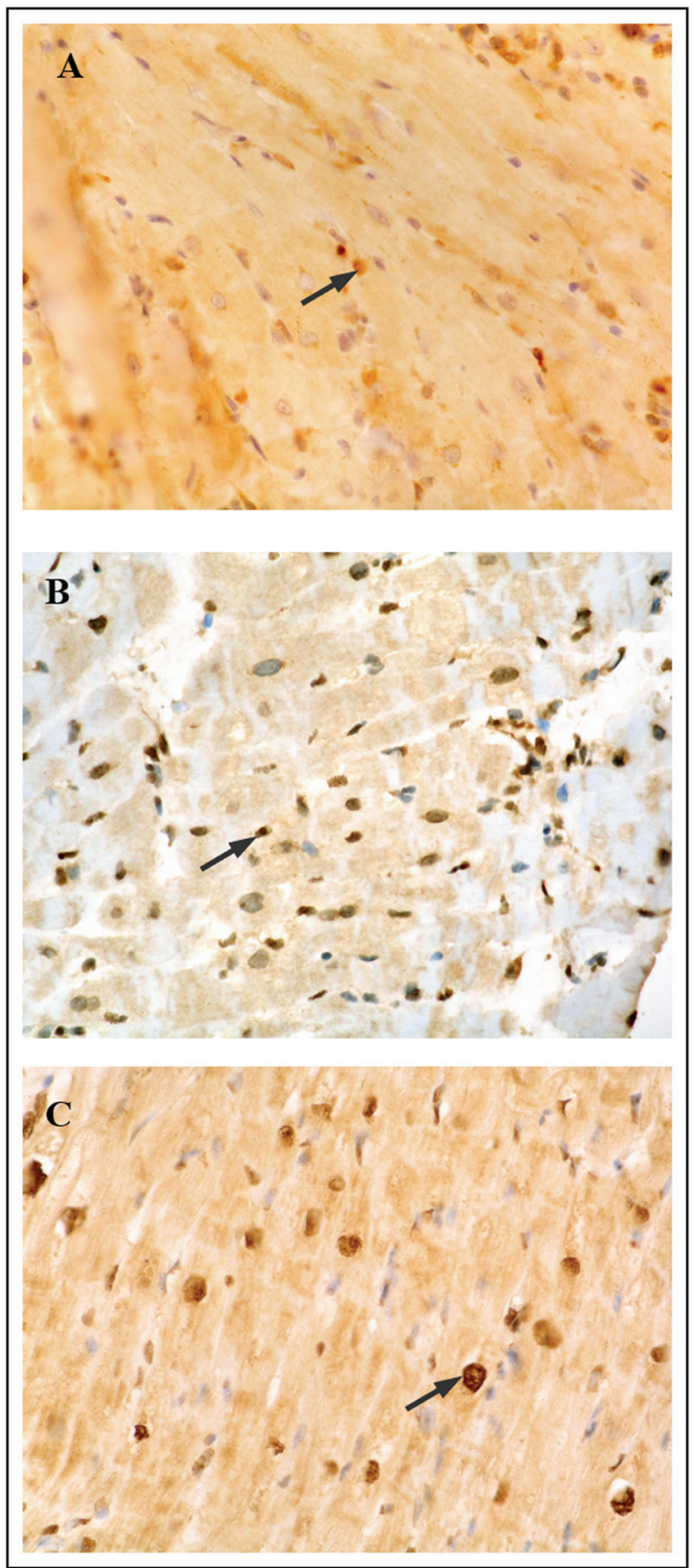

Fig. 3. Immunohistochemical staining of graft specimen; arrows show bcl-2 positive nucleus (A), caspase-3 positive nucleus (B) and TUNEL positive nucleus (C).

transplantation. Birks et al. (2000) demonstrated that caspases were elevated in dysfunctional donor hearts compared to hearts with good ventricular function. Significantly higher expression levels of genes involved in apoptosis (BAX, caspase-3 and FAS) in donor hearts compared with control patients were shown in Stoica et al. (2008). This supports the concept that brain death may 
cause the activation of apoptosis, with a possible important effect on cardiac function. In a small prospective study by Chalabreysse et al. (2004), apoptosis was determined from right ventricle biopsies from brain-dead donors. The authors confirmed that brain death induces apoptosis in the right ventricle, but a high apoptotic index does not correlate with subsequent myocardial function in the grafted heart and does not predict myocardial dysfunction during the first postoperative year. There is only one study that examined what effect apoptosis in donor hearts immediately before transplantation had on the onset of PGD in recipients (Marasco et al. 2014). Significantly raised levels of caspase-3 specific activity, activated hypoxia inducible factor-1 and 8-hydroxy-2'-deoxyguanosine were present in the transplanted hearts that developed PGD. Importantly, unlike our investigation and the Chalabreysse study, they did not obtain samples from the ventricular myocardium, but only the left atrium and they did not reveal direct evidence of ventricular apoptotic processes that may have exhibited a differing extent of effects.

In conclusion, our finding does not demonstrate an association between measured myocardial cell death, necrosis and apoptosis markers in donor myocardium and PGD in allograft recipients. More detailed investigations of cell death signaling pathways and focuses on other types of cell death (autophagy) in transplanted hearts are required.

\section{Conflict of Interest}

There is no conflict of interest.

\section{Acknowledgements}

This study was supported by the Internal Grant Agency of the Ministry of Health of the Czech Republic No. NT/11269-5.

\section{References}

ATKINSON C, FLOERCHINGER B, QIAO F, CASEY S, WILLIAMSON T, MOSELEY E, STOICA S, GODDARD M, GE X, TULLIUS SG, TOMLINSON S: Donor brain death exacerbates complement-dependent ischemia/reperfusion injury in transplanted hearts. Circulation 127: 1290-1299, 2013.

BIRKS EJ, YACOUB MH, BURTON PS, OWEN V, POMERANCE A, O'HALLORAN A, BANNER NR, KHAGHANI A, LATIF N: Activation of apoptotic and inflammatory pathways in dysfunctional donor hearts. Transplantation 70: 1498-1506, 2000.

BOCCHECIAMPE N, AUDIBERT G, RANGEARD O, CHARPENTIER C, PERRIER JF, LALOT JM, VOLTZ C, STRUB P, LOOS-AYAV C, MEISTELMAN C, MERTES PM, LONGROIS D: Serum troponin Ic values in organ donors are related to donor myocardial dysfunction but not to graft dysfunction or rejection in the recipients. Int J Cardiol 133: 80-86, 2009.

CHALABREYSSE L, LEROUX C, OBADIA JF, GREENLAND T, THIVOLET-BEJUI F, MORNEX JF: Apoptosis in right-ventricle biopsy is not predictive of graft survival. Transpl Int 17: 362-365, 2004.

D'ALESSANDRO C, AUBERT S, GOLMARD JL, PRASCHKER BL, LUYT CE, PAVIE A, GANDJBAKHCH I, LEPRINCE P: Extra-corporeal membrane oxygenation temporary support for early graft failure after cardiac transplantation. Eur J Cardiothorac Surg 37: 343-349, 2010.

D'ANCONA G, SANTiSE G, FALlETTA C, PIRONE F, SCIACCA S, TURRISi M, BIONDO D, PILATO M: Primary graft failure after heart transplantation: the importance of donor pharmacological management. Transplant Proc 42: 710-712, 2010.

DEIBERT E, BARZILAI B, BRAVERMAN AC, EDWARDS DF, AIYAGARI V, DACEY R, DIRINGER M: Clinical significance of elevated troponin I levels in patients with nontraumatic subarachnoid hemorrhage. J Neurosurg 98: 741-746, 2003.

ERBEL C, TASKIN R, DOESCH A, DENGLER TJ, WANGLER S, AKHAVANPOOR M, RUHPARWAR A, GIANNITSIS E, KATUS HA, GLEISSNER CA: High-sensitive Troponin T measurements early after heart transplantation predict short- and long-term survival. Transpl Int 26: 267-272, 2013.

GIANNITSIS E, KATUS HA: Troponins and high-sensitivity troponins as markers of necrosis in CAD and heart failure. Herz 34: 600-606, 2009. 
IBRAHIM M, HENDRY P, MASTERS R, RUBENS F, LAM BK, RUEL M, DAVIES R, HADDAD H, VEINOT JP, MESANA T: Management of acute severe perioperative failure of cardiac allografts: a single-centre experience with a review of the literature. Can J Cardiol 23: 363-367, 2007.

IYER A, KUMARASINGHE G, HICKS M, WATSON A, GAO L, DOYLE A, KEOGH A, KOTLYAR E, HAYWARD C, DHITAL K, GRANGER E, JANSZ P, PYE R, SPRATT P, MACDONALD PS: Primary graft failure after heart transplantation. $J$ Transplant 2011: 175768, 2011.

KHUSH KK, MENZA RL, BABCOCK WD, ZAROFF JG: Donor cardiac troponin I levels do not predict recipient survival after cardiac transplantation. $J$ Heart Lung Transplant 26: 1048-1053, 2007.

KOBASHIGAWA J, ZUCKERMANN A, MACDONALD P, LEPRINCE P, ESMAILIAN F, LUU M, MANCINI D, PATEL J, RAZI R, REICHENSPURNER H, RUSSELL S, SEGOVIA J, SMEDIRA N, STEHLIK J, WAGNER F; CONSENSUS CONFERENCE PARTICIPANTS: Report from a consensus conference on primary graft dysfunction after cardiac transplantation. J Heart Lung Transplant 33: 327-340, 2014.

LIMA B, RAJAGOPAL K, PETERSEN RP, SHAH AS, SOULE B, FELKER GM, ROGERS JG, LODGE AJ, MILANO CA: Marginal cardiac allografts do not have increased primary graft dysfunction in alternate list transplantation. Circulation 114: I27-I32, 2006.

MAJNO G, JORIS I: Apoptosis, oncosis, and necrosis. An overview of cell death. Am J Pathol 146: 3-15, 1995.

MARASCO SF, KRAS A, SCHULBERG E, VALE M, LEE GA: Impact of warm ischemia time on survival after heart transplantation. Transplant Proc 44: 1385-1389, 2012.

MARASCO SF, SHEERAN FL, CHAUDHURI K, VALE M, BAILEY M, PEPE S: Molecular markers of programmed cell death in donor hearts before transplantation. J Heart Lung Transplant 33: 185-193, 2014.

MÉNDEZ AB, CARDONA M, ORDÓÑEZ-LLANOS J, MIRABET S, PEREZ-VILLA F, ROIG E: Predictive value of high-sensitive troponin $\mathrm{T}$ to rule out acute rejection after heart transplantation. Rev Esp Cardiol 67: 775-776, 2014.

OTO T, EXCELL L, GRIFFITHS AP, LEVVEY BJ, BAILEY M, MARASCO S, MACDONALD P, SNELL GI: Association between primary graft dysfunction among lung, kidney and heart recipients from the same multiorgan donor. Am J Transplant 8: 2132-2139, 2008.

POTAPOV EV, IVANITSKAIA EA, LOEBE M, MÖCKEL M, MÜLLER C, SODIAN R, MEYER R, HETZER R: Value of cardiac troponin $\mathrm{I}$ and $\mathrm{T}$ for selection of heart donors and as predictors of early graft failure. Transplantation 71: 1394-1400, 2001.

RUSSO MJ, IRIBARNE A, HONG KN, RAMLAWI B, CHEN JM, TAKAYAMA H, MANCINI DM, NAKA Y: Factors associated with primary graft failure after heart transplantation. Transplantation 90: 444-450, 2010.

SEGOVIA J, COSÍO MD, BARCELÓ JM, BUENO MG, PAVÍA PG, BURGOS R, SERRANO-FIZ S, GARCÍAMONTERO C, CASTEDO E, UGARTE J, ALONSO-PULPÓN L: RADIAL: a novel primary graft failure risk score in heart transplantation. J Heart Lung Transplant 30: 644-651, 2011.

STOICA SC, SATCHITHANANDA DK, ATKINSON C, CHARMAN S, GODDARD M, LARGE SR. Heat shock protein, inducible nitric oxide synthase and apoptotic markers in the acute phase of human cardiac transplantation. Eur J Cardiothorac Surg 24: 932-939, 2003. 